\title{
On a simple and ready way of producing tools for grinding lenses
}

\section{N.S. Heineken}

To cite this article: N.S. Heineken (1848) On a simple and ready way of producing tools for grinding lenses, Philosophical Magazine Series 3, 33:224, 480-481, DOI: $10.1080 / 14786444808646146$

To link to this article: http://dx.doi.org/10.1080/14786444808646146

曲 Published online: 30 Apr 2009.

Submit your article to this journal $₫$

Џ Article views: 2

Q View related articles $₫$ 
already cited) diminished by the constant $0.4957, \mathrm{~B}$ is the barometer reading in English inches, and $T$ is the thermometer reading in degrees of Fahrenheit (Bessel's $\log \alpha^{\prime \prime}$ takes account approximately of the variation depending on zenith distance of the factor $A$ in the expression, $A$ tan zen. dist. for the total refraction). To select the proper value of $\log k$, the argument zenith distance $(z)$ is first obtained by the formula, $\sec z=\sec Q Z \sec (\Delta-\mathrm{PQ})$. The calculations are much facilitated by the formation of two tables ; one containing the values of $P Q, \log \sec Q Z$, and $\log \frac{\tan Q Z}{15}$, for every ten minutes of hour angle from $0^{\mathrm{h}}$ to $6^{\mathrm{h}}$, whence, by interpolation, and by proper attention to changes of sign, the values may be obtained for any given hour-angle; the other, a table of values of $\log k$, in which the argument is $z$, or, which is preferable, $\log \sec z$, the difference between the consecutive logarithms being 0.01 .

In an instance in which the apparent difference of north polar distance was $32^{\prime} \cdot 1$, the hour-angle $3^{\mathrm{h}} 49^{\mathrm{m} \cdot} \cdot 7$, and the zenith distance $82^{\circ} \cdot 3$, the corrections calculated by the above approximate formulæ were $18^{\prime \prime} \cdot 12$ and $0^{3 \cdot 769}$. By exact calculation they were found to be $18^{\prime \prime} \cdot 27$ and $0^{3 \cdot 762 \text {. }}$

When differences of right ascension and north polar distance are measured while the equatoreal is carried by clock-movement (which is sometimes done with the Northumberland equatoreal), it is necessary to compute exactly the total refractions in right ascension and north polar distance of each object, no other method appearing to possess sufficient accuracy.

Extract of a Letter from Mr. Alfred Weld, Director of the Observatory at Stonyhurst College.

"On September 20, I observed a large spot on the sun with our equatoreal, and found that it consisted of several dark nuclei enveloped in one large penumbra. On the 21 st, I made several observations, from which I deduced the following values of the angles subtended by the spot and nucleus :-

$$
\begin{aligned}
& \text { Greatest diameter of spot ........ } \quad \dot{z}_{41}^{41} \cdot 1 \\
& \text {... } \quad \ldots \quad \text { nucleus ....... } 17.2 \\
& \text { Equatoreal diameter of spot } \ldots . . .2 \quad 2 \quad 14 \cdot 1 \\
& \begin{array}{lllll} 
& . . & \text { nucleus ... } & 0 & 49.2
\end{array}
\end{aligned}
$$

"The spot was distinctly visible to the naked eye before sunset." By comparisons with $\delta$ Ophiuchi, Spica and Antares, Mr. Weld found the declination of Mr. Hind's changing star to be $-12^{\circ} 37^{\prime} 15^{\prime \prime}$.

LXXI. Intelligence and Miscellaneous Articles.

\section{ON A SIMPLE AND READY WAY OF PRODUCING TOOLS FOR GRINDING LENSES. BY N. S. HEINEKEN.}

\section{To the Editors of the Philosophical Magazine and Journal.}

Gentuemen,

Sidmouth, Nov. 15, 1848.

F you think the following simple and ready way of producing tools for grinding lenses likely to be of service to any of the 
readers of the Philosophical Magazine, you will oblige me by making it known. I was led to employ this method in consequence of an injury done to a lens, for the regrinding of which $I$ had no corresponding brass tool. Rather than take the trouble of making a set of brass gauges and also a set of grinding-tools, I took a cast of the lens itself by pressure upon the cooling surface of some fusible metal contained in a frame of card. On this tool, thus readily formed, I reground and polished the lens; and where great accuracy of figure is not required, have found the method to answer very well. Hoping that this plan may be useful to others who may meet with a similar casualty, I communicate it. Perhaps I may also be allowed to mention, that I have found zinc exceedingly useful for the formation of ordinary grinding-tools, being readily cast and turned; and though not equal to brass, yet being in many respects superior to the soft metal tools sometimes employed.

I am, Gentlemen,

Respectfully yours,

N. S. HEINEKEN.

\section{DR, BIALLOBLOTZKY'S JOURNEY TO THE SOURCES OF THE NILE.}

Letters have been received by Dr. Beke from Dr. Bialloblotzky, whose intended exploratory journey into Eastern Africa was noticed in the last Number of the Philosophical Magazine*, by which letters that traveller's proceedings are brought down to the 8 th of November, when he was at Alexandria.

Before Dr. Bialloblotzky quitted Vienna on the 7th of October, the Imperial Academy of Sciences granted him the use of some valuable instruments made by M. Kapeller of Gumpendorf and selected by M. Schaubl of the Imperial Observatory, and the Government procured for him and his son a passage gratis from Vienna to Trieste by the railway, and from Trieste to Athens, Syra and Alexandria, by the steamers of the Austrian Lloyd's.

It was his intention to quit Suez for Aden on the 23rd of November by the East India Company's steam-packet, by which a free passage has been granted to him by the Court of Directors.

\section{ON THE ARSENITES OF IRON.}

M. Filhol made a few experiments on the arsenites of iron with the view of discovering a certain method of ascertaining the state in which arsenic exists in chalybeate waters and the deposits which they form; the author states that he did not find what he looked for, but still he observed some facts which he deemed not unimportant.

Arsenic does not always exist in chalybeate waters in the state either of arsenite or arseniate, and its presence in certain ferruginous deposits may not be recognized, on account of the state in which it exists.

In proceeding to analyse a deposit from a spring at a little distance * See page 399 . 